\title{
Propagation of pistachio applying in vitro culture techniques
}

\author{
J.A. Marín, E. García, P. Lorente, A. Arbeloa and P. Andreu \\ Estación Experimental de Aula Dei-CSIC. \\ Avenida Montañana 1005. \\ 50059 Zaragoza. \\ e-mail:jmarin@eead.csic.es
}

Key words: Pistacia vera, Pistacia terebinthus, micropropagation, grafting, Larnaka, Kerman, Sirora, Peters.

\begin{abstract}
Pistachio grafting often shows a high degree of uncertainty, with variable and inconsistent results with commonly used rootstocks, producing irregular orchards and frequent regrafting. Besides, the size of the buds of pistachio cultivars far exceeds that of the juvenile rootstock terebinth (Pistacia terebinthus L.), widely used in Spain, making pistachio grafting more difficult.

Here, we have applied in vitro techniques to obtain reduced-size cultivars that match to the rootstock size. By reducing bud/scion of pistachio cultivars we can thus graft them on terebinth seedlings few weeks after germination. The female cultivars 'Larnaka', 'Kerman' and 'Sirora', as well as the male cultivar 'Peters' and the selection AD15 have been successfully cultivated in vitro.

Grafting was performed on juvenile terebinth plants grown in small containers using a) micropropagated and acclimatized pistachio plants or b) in vitro grown shoot-tips as scion source. We have got up to $68 \%$ successful grafts with scions derived from in vitro techniques. Scions resumed growth few days after grafting, and time required to obtain new plants was significantly shortened.
\end{abstract}

\section{INTRODUCTION}

Pistachio (Pistacia vera L.) is becoming a highly interesting crop in Spain. However, pistachio plant production does not match the existing demand and this deficit slows down the expansion of the crop. This is mainly due to the difficulty of grafting on terebinth rootstocks that limits plant supply and raises plant price.

Graft success in pistachio depends on numerous factors: temperature, humidity, rootstock activity etc. Besides, bud size of pistachio cultivars should match those of rootstocks (Guerrero et al., 2004). Terebinth (Pistacia terebinthus L.), an autochthonous species well adapted to Spanish cold climates, soils and tolerant to soil diseases (Guerrero et al., 2002; 2007), is widely used in Spain, although the reduced size due to its moderate vigor make that pistachio cultivars bud size far exceeds that of the rootstock. Grafting is therefore made after two years of rootstock growth in the nursery or in orchards, where grafting failure produces irregular orchards and frequent regrafting.

In this work, we have applied in vitro techniques to obtain reduced-size cultivars that better match to the rootstock size. In vitro culture of Pistacia juvenile explants (Barghchi and Alderson, 1989; Ozden-Tokatli et al., 2005; Benmahioul et al., 2009; Yildirim, 2012) or adult explants (Onay, 2000; Tilkat et al., 2009a) from local Turkish cultivars 'Siirt' or 'Antep' have been previously achieved. However, attempts to reproduce these protocols with the cultivars studied here failed. Major limitations of pistachio micropropagation still are contamination and the exudation of phenolic 
compounds that occur during the establishment of the cultures causing the explants death (Tabiyeh et al., 2006; Onay et al., 2007). In addition, low morphogenetic capacity of adult material and tip necrosis of shoots limited pistachio micropropagation (García et al., 2011). Besides, micrografting in vitro has been done with 'Mateur' or 'Siirt' cultivars trying to rejuvenate plant material (Abousalim and Mantell, 1992; Onay et al., 2004), not for propagation purposes, as we aim here.

In this paper, we propose a different approach to pistachio grafting by using in vitro culture techniques, providing a suitable, flexible and easier to control model. Grafting in vitro-cultured-cultivar scions either from micropropagated and acclimatized pistachio plants, or in vitro grown shoot-tips, on terebinth seedling rootstocks might be a successful and quick technique to obtain pistachio plants.

\section{MATERIALS AND METHODS}

\section{In vitro establishment of Pistacia vera cultivars}

Explants from the female cultivars 'Larnaka', 'Kerman' and 'Sirora', the male cultivar 'Peters', as well as from the selection AD15 were taken from field grown plants in spring, using antioxidants during explants preparation and processing (ascorbic acid and citric acid both at $1 \mathrm{mM}$ ). Explants were disinfected either with $0.05 \% \mathrm{HgCl} 2$ or with diluted bleach $(10 \mathrm{~g} / \mathrm{L}$ active $\mathrm{Cl})$. One-node explants were cultured in modified DKW medium (Driver and Kuniyuki, 1984) with ascorbic acid $(0.01 \mathrm{~g} / \mathrm{L})$ for two months in the culture chamber at $22^{\circ} \mathrm{C}$ under a $16 \mathrm{~h}$ photoperiod with cool-white fluorescent tubes $\left(35 \mu \mathrm{mol} \mathrm{m} \mathrm{m}^{-2} \mathrm{~s}^{-1}\right)$. New shoots were transferred onto jars with $30 \mathrm{ml}$ fresh medium for multiplication. Percentages of contamination and bud break were recorded after two months.

\section{In vitro multiplication and acclimatization}

Two culture media were tested for multiplication following previous works (García et al, 2010; 2011; 2012): a modified DKW medium (Driver and Kuniyuki, 1984) and a modified LP medium (Long et al., 1995) both supplemented with $0.1 \mathrm{mg} / \mathrm{L}$ IBA, $1 \mathrm{mg} / \mathrm{L}$ meta-Topolin, $0.2 \mathrm{mg} / \mathrm{L}$ kinetin, $0.01 \mathrm{~g} / \mathrm{L}$ ascorbic acid, $30 \mathrm{~g} / \mathrm{L}$ sucrose, and $7 \mathrm{~g} / \mathrm{L}$ agar (Bacto-agar, Difco, Fisher Scientific) to grow different pistachio cultivars.

Cultures were maintained in a culture chamber as previously described. Shoots were subcultured every three weeks and multiplication rates were recorded.

Rooting of AD15 selection (P.vera) shoots was achieved in a modified MS medium with half-strength macronutrients, $1 \mathrm{mg} / \mathrm{L} \mathrm{IBA}, 2 \mathrm{mg} / \mathrm{L}$ paclobutrazol and without BAP. Rooting percentage was recorded after 4-8 weeks.

Acclimatization of the rooted shoots was performed in plastic enclosures either in the greenhouse or in a culture chamber with a more precise control of the environment ( $400 \mu \mathrm{E}$ light intensity, $16 \mathrm{~h}$ photoperiod, $25^{\circ} \mathrm{C}$ and $70 \% \mathrm{RH}$ ). A protocol based on short exposures to low RH that increased steadily with time was followed (Marín, 2003).

\section{Terebinth seedling production}

Terebinth $(P$. terebinthus) mature seeds were washed in distilled water after peeling, dried, and cold stored at $4-5^{\circ} \mathrm{C}$ for at least 5 months. Seeds were later sowed in forestall cells containing Pindstrup substrate, a proprietary mixture of peat:perlite (Pindstrup Mosebrug S.A.E. professional substrate) and maintained in a greenhouse. 


\section{Grafting acclimatized shoots}

Grafting scions from micropropagated and acclimatized pistachio AD15 plants was performed in the greenhouse on terebinth seedling rootstocks using the cleftgrafting technique.

Four week old seedlings of $P$. terebinthus were decapited and a vertical slit was made on their top. Scions $(n=46)$ containing a lateral bud from acclimatized P.vera AD15 plants were cut in v-shape and fitted onto the slit. Mechanical fixation of the grafting area was achieved with a thin silicon tube (1.5 $\mathrm{mm}$ inner diameter).

Graft evaluations were made at 1 and 3 weeks after grafting when buds resumed growth, and survival rates were calculated.

\section{Grafting in vitro shoot tips}

A second grafting type was performed with scions from in vitro grown shoottips of different cultivars on seedling terebinth rootstocks. Rootstock seedlings were prepared in a similar way and decapitated four weeks after germination. Shoot-tip scions from in vitro cultures of the female cultivars 'Larnaka' and 'Kerman' and the male cultivar 'Peters' ( $n$ ranged from 33 to 37 grafts per cultivar) were cut in v-shape and fitted onto the vertical slit of decapitated rootstocks. Mechanical fixation of the graft was made as above.

Grafted plants should later follow an acclimatization process similar to rooted plants coming from in vitro cultures as described above.

\section{RESULTS AND DISCUSSION}

\section{In vitro establishment and culture of Pistacia cultivars}

Five cultivars of pistachio: 'Peters' (male), 'Larnaka', 'Kerman', 'Sirora' (females) and the selection AD15 have been successfully established in vitro. Considering the contamination level and that bud break rates were low (Table 1), mainly due to browning problems, a large number of explants should be thus introduced to succeed. Excessive browning of both the explants and the culture medium that could cause the death of the cultures is a common fact in the establishment of pistachio cultures from mature field-grown trees (Dolcet and Clavería, 1995; Ozden-Tokatli et al., 2005; Leng et al., 2009). The use of antioxidants during explants preparation and processing, as well as in the culture medium resulted beneficial in our cultures, achieving the in vitro establishment of all tested cultivars.

Established cultures were successfully in vitro grown once the protocols were adapted. Among the various media tested (García et al., 2010; 2011), a modified DKW medium (Driver and Kuniyuki, 1984) gave the best results for 'Larnaka', 'Sirora' and AD15, while 'Peters' and 'Kerman' performed better in LP walnut media (Long et al., 1995).

Multiplication rates were calculated for each cultivar in their optimal culture media (Figure 1). They showed an adequate in vitro adaptation of all cultivars once antioxidants were added to the culture media to avoid browning and abundant exudates in the culture medium, which is considered one of the main problems in pistachio in vitro culture (Tabiyeh et al., 2006). In addition, hormonal combinations without BAP reduced the appearance of shoot tip necrosis. Cytokinins have been pointed out as the most determinant factor (Barghchi and Alderson, 1989; García et al., 2011). The combination of meta-Topolin and kinetin gave healthier and longer shoots than BAP making possible an effective multiplication of shoots. 
Rooting and acclimatization of pistachio AD15 shoots resulted critical and long lasting phases. Lack of rooting and synchrony, or a scarce root number per shoot were frequent in pistachio propagation (Onay, 2000; Tilkat et al., 2009b; García et al., 2010). For pistachio AD15, although good rooting rate was achieved (90\%), acclimatization was poor. High survival rates during acclimatization were hampered by the lack of visual symptoms of wilting. A protocol based on short exposures to low RH that increased steadily with time should be followed (Marín, 2003), as well as a precise control of the environment. Acclimatization in a culture chamber environment $(400 \mu \mathrm{E}$ light intensity, $16 \mathrm{~h}$ photoperiod, $25^{\circ} \mathrm{C}$ and $70 \% \mathrm{RH}$ ) raised plant survival up to $80 \%$ from a mere $10 \%$ in the greenhouse.

For most of the cultivars, rooting and acclimatization are still long and hard processes, so to have a grafting procedure that uses shoots coming directly from in vitro culture resulted in a great advantage.

\section{Grafting success}

By applying in vitro techniques we have achieved reduced-size cultivars that match to the rootstock size. Grafting scions derived from in vitro techniques on juvenile terebinth plants gave up to $68 \%$ successful grafts, depending on the cultivar. Successful grafts showed healthy and turgent small shoots few days after grafting (Figure 2) and survival rates at week 3 are shown in Table 2. While grafts from micropropagated and acclimatized pistachio AD15 scion gave a survival rate of $61 \%$, we got a genotype dependent survival using in vitro grown shoot-tips. Thus, grafts from 'Larnaka' and 'Kerman' gave similar grafting survival rates as the acclimatized AD15, whereas 'Peters' gave a much lower survival. On the other hand, acclimatization of in vitro shoottip grafted plants was easier and faster than that of in vitro rooted pistachio shoots, lasting only one or two weeks.

In vitro micrografting has been rarely tried with success in pistachio (Onay et al., 2004; 2007) using in vitro growing shoots of $P$. vera, either as scion or as rootstock. Besides, in vivo grown scions grafted onto in vitro seedlings failed (Can et al., 2006).

Ex vitro grafting of shoots that are produced in vitro is an uncommon technique that has been used mainly to rescue transgenic rootless shoots (Yang et al., 2000; Weber et al., 2003) or somatic embryo rescue in avocado (Raharjo and Litz, 2005).

Here grafting non acclimatized in vitro shoot tips resulted in a great advantage due, not only to a relatively high graft success, but to shorten time and facilitate pistachio propagation.

\section{CONCLUSIONS}

The method presented is based on the reduction of the scion size during in vitro culture, which makes possible its grafting on small-size rootstocks and improves the response to grafting.

The female cultivars 'Larnaka', 'Kerman' and 'Sirora', as well as the male cultivar 'Peters' have been successfully cultivated in vitro. Works are in progress to increase the number of varieties cultured in vitro.

Grafting ('micrografting') was successfully performed on juvenile terebinth plants grown in small containers, which adds great flexibility to plant management. In addition, time required to obtain new plants was shortened significantly.

Terebinth seedlings were used as rootstocks in all cases, but the technique can be extended to other rootstocks. 


\section{ACKNOWLEDGEMENTS}

This work was partly funded by the INIA-FEDER RTA2010-00053-C03 project and by Group A-43 Excellence grant by the Government of Aragon. Substrate was kindly provided by Pindstrup Mosebrug S.A.E. (Sotopalacios, Spain)

\section{Literature Cited}

Abousalim A.and Mantell S.H. 1992. Micrografting of pistachio (Pistacia vera L. cv. Mateur). Plant Cell, Tissue and Organ Culture 29, 231 - 234

Barghchi M. and Alderson P.G. 1989. Pistachio (Pistacia vera L.). In: Bajaj, Y.P.S. (Ed.), Biotechnology in agriculture and forestry. Vol.5. Trees II. SpringerVerlag, Berlin, Heidelberg, pp. 68-98.

Benmahioul, B., Kaid-Harche, M., Dorion, N. and Daguin, F. 2009. In vitro embryo germination and proliferation of pistachio (Pistacia vera L.). Scientia Horticulturae 122 (3): 479-483.

Can C., Ozaslan M., Toremen H., Sarpkaya K. and Iskender E. 2006. In vitro micrografting of pistachio, Pistacia vera L. var. Siirt, on wild pistachio rootstocks. Journal of Cell and Molecular Biology, 5:25-31

Dolcet-San Juan R. and Clavería E. 1995. Improved shoot-tip micropropagation of Pistacia vera L. and the beneficial effects of methil jasmonate. J. Amer. Soc. Hort. Sci., 120(6): 938-942

Driver, J.A. and Kuniyuki, A.H. 1984. In vitro propagation of Paradox walnut rootstock. HortScience 19: 507-509.

García E., Lorente P., Marín J.A., Arbeloa A. and Andreu P. 2010. Micropropagación e injerto in vitro de pistacho. ITEA 106(4): 294 -302

García E., Lorente P., Marín J.A., Andreu P. and Arbeloa A. 2011. Factores que afectan a la necrosis apical de brotes de Pistacia vera cultivados in vitro. ITEA 107 (4): $315-323$.

García E., Imbroda I., Lorente P., Marín J.A., Arbeloa A., Padilla I.M.G., Barceló A. and Andreu P. 2012. Micropropagation and in vitro grafting techniques to assist the selection of a pistachio rootstock from a population of terebinth (Pistacia terebinthus L.) collected in the SE of Spain. Acta Horticulturae, 961: 245-252

Guerrero J., Couceiro J.F. and Moriana A. 2002. Selection of Terebinth (Pistacia terebinthus $\mathrm{L}$.) trees as seed producers for pistachio (Pistacia vera $\mathrm{L}$ ) rootstocks in the Castilla La Mancha (Spain). FAO-Nucis-Newsletter (11): 25-29

Guerrero J., Moriana A. and Couceiro J.F. 2004. La operación de injerto en Pistachero (Pistacia vera L.) condicionantes en Castilla La Mancha. Fruticultura Profesional (140): 41-53.

Guerrero J., Couceiro J.F., Moriana A., Gijon M.C. and Rivero A. 2007. El pistachero $(P$. vera L.) en Castilla-La Mancha. Comportamiento en secano de diferentes cultivares y portainjertos. Actas de Horticultura 48: 635-638

Leng L., Su S., Wei F., Yu F. and Duan Y. 2009. Correlation between browning, total phenolic content, polyphenol oxidase and several antioxidation enzymes during pistachio tissue culture. Acta Horticulturae 829: 127-131

Long, L.M., Preece, J.E. and Van Sambeek, J.W. 1995 Adventitious regeneration of Juglans nigra L. (eastern black walnut) Plant Cell Reports 14: 799-803

Marín, J.A. 2003. High survival rates during acclimatization of micropropagated fruit tree rootstocks by increasing exposures to low relative humidity. Acta Horticulturae 616:139-142

Onay A. 2000. Micropropagation of Pistachio from mature trees. Plant Cell Tissue and Organ Culture, 60: 159-163. 
Onay A., Virinç V., Yildirim H. and Basaran D. 2004. In vitro micrografting of mature pistachio (Pistacia vera var. Siirt). Plant Cell Tissue and Organ Culture, 77:215219

Onay A., Tilkat E., Isikalan C. and Namli S. 2007. Micrografting of pistachio (Pistacia vera L. cv. Siirt). In: Protocols for Micropropagation of Woody Trees and Fruits. Chapter 27:289-298. S M Jain and H Haggman Eds. Springer.

Ozden-Tokatli Y., Ozudogru E.A. and Akcin A. 2005. In vitro response of pistachio nodal explants to silver nitrate. Scientia Horticulturae 106:415-426

Raharjo S. and Litz E. 2005. Micrografting and ex vitro grafting for somatic embryo rescue and plant recovery in avocado (Persea americana) Pant Cell Tissue and Organ Culture 82: 1-9

Tabiyeh D.T., Bernard F. and Shacker H. 2006 Investigation of glutathione, salicylic acid and GA3 effects on browning in Pistacia vera shoot tips. Acta Horticulturae 726: 201-203

Tilkat E., Onay A., Yildirim, H. and Ayaz, E. 2009a. Direct plant regeneration from mature leaf explants of pistachio, Pistacia vera L. Scientia Horticulturae. 121: 361-365

Tilkat E., Onay A. and Ozden Y. 2009b. In vitro rooting improvement of adult Pistachio, Pistacia vera L. "Atli". Acta Horticulturae 839: 215-221

Weber S., Friedt W., Landes N., Molinier J. Himber C., Rouselin P., Hahne G. and Horn R. 2003. Improved Agrobacterium-mediated transformation of sunflower (Helianthus annus L.) assessment of macerating enzymes and sonication. Plant Cell Reports 21: 475-482

Yang Z.N., Ingelbrecht I.L., Louzada E., Skaria M. and Mirkov T.E. 2000. Agrobacterium-mediated transformation of the commercially important grapefruit cultivar Rio Red (Citrus paradisi Macf.). Plant Cell Report 19: 12031211

Yildirim, H. 2012. Micropropagation of Pistacia lentiscus L. from axenic seedlingderived explants. Scientia Horticulturae, 137:29-35 


\section{Tables}

Table 1. Establishment of cultivars showing contamination and bud break percentages

\begin{tabular}{|l|l|l|l|l|}
\hline Cultivar & Explants & Contaminated & Bud break & $\%$ Bud break \\
\hline Kerman & 110 & 13 & 20 & 20,6 \\
\hline Larnaka & 132 & 9 & 41 & 33,3 \\
\hline Peters & 120 & 20 & 9 & 9 \\
\hline Sirora & 14 & 0 & 3 & 21.4 \\
\hline AD15 & 33 & 0 & 14 & 42.4 \\
\hline
\end{tabular}

Table 2. Graft evaluation and survival of micropropagated and acclimatized pistachio AD15 plants, and in vitro shoot-tips of different cultivars, on terebinth seedlings

\begin{tabular}{|c|c|c|c|c|c|}
\hline Scion type & Cultivar & $\begin{array}{c}\text { Number } \\
\text { of grafts }\end{array}$ & $\begin{array}{c}\text { Healthy grafts } \\
\text { (1 week) }\end{array}$ & $\begin{array}{c}\text { Survival } \\
\text { (3 weeks) }\end{array}$ & $\begin{array}{c}\text { \% } \\
\text { Survival }\end{array}$ \\
\hline Acclimatized & AD15 & 46 & 8 & 28 & 61 \\
\hline \multirow{3}{*}{ In vitro shoot tip } & Larnaka & 37 & 30 & 28 & 68 \\
\cline { 2 - 6 } & Kerman & 33 & 25 & 19 & 52 \\
\cline { 2 - 6 } & Peters & 36 & 12 & 6 & 17 \\
\hline
\end{tabular}




\section{$\underline{\text { Figures }}$}

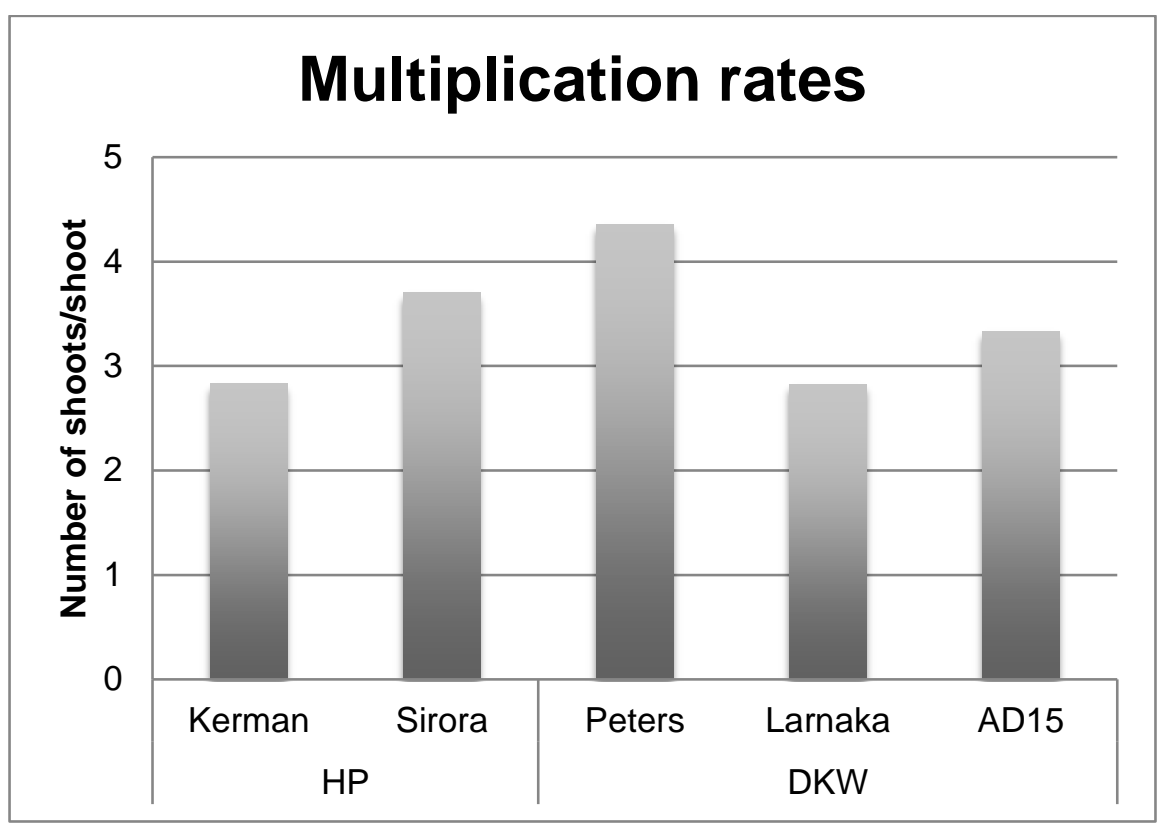

Figure 1. Multiplication rates of pistachio cultivars grown in their preferred media
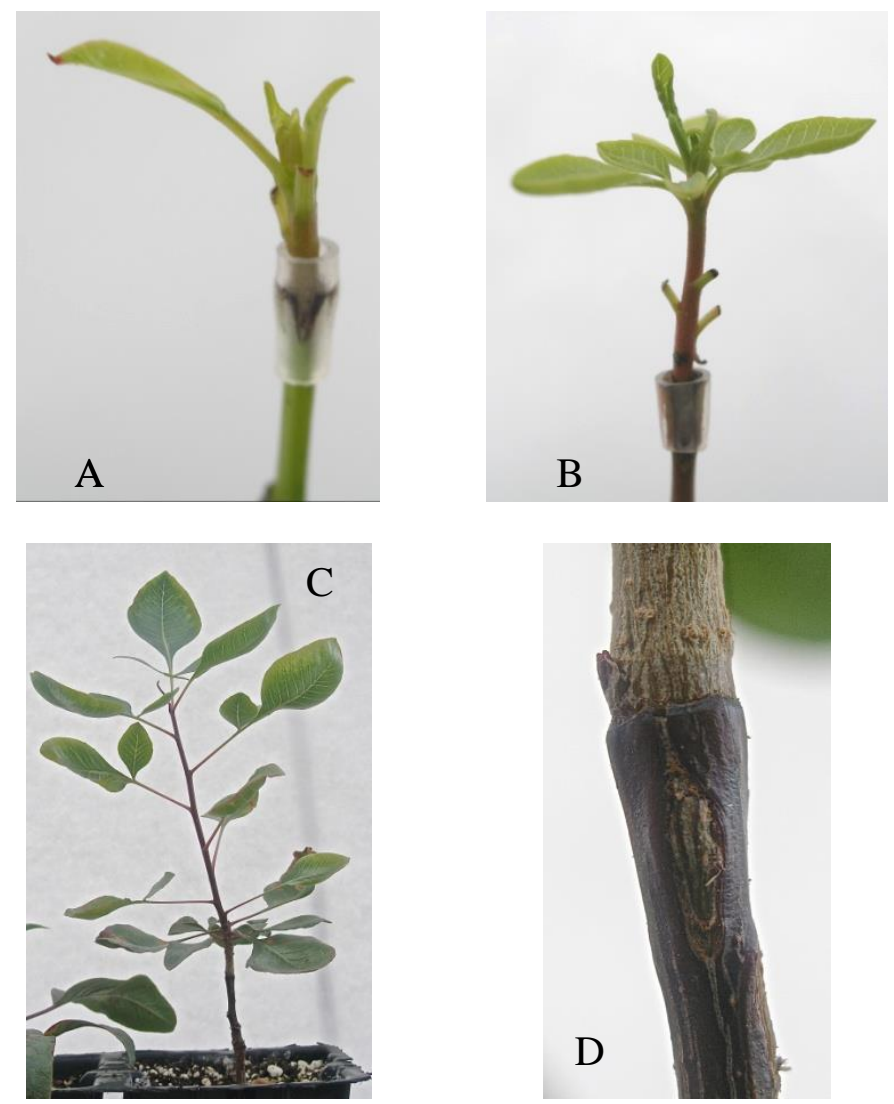

Figure 2. P.vera 'Larnaka' on terebinth rootstock. In vitro shoot-tip grafted on terebinth seedling (A); growth after one week (B); established plant after 3 months (C); detail of the graft after 3 months (D). 